\title{
LA AGRICULTURA A TIEMPO PARCIAL EN EL PAÍS VALENCIÀ. COMENTARIOS AL CENSO AGRARIO DE 1982
}

\author{
Rafael Viruela Martínez
}

\section{RESUMEN}

En los últimos años, la agricultura a tiempo parcial ha adquirido una importancia creciente en el País Valencià, a tal punto que la tierra ha dejado de ser la principal fuente de ingresos en muchos hogares, adquiriendo cada vez más el carácter de complementariedad.

La pluriactividad no sólo afecta a los titulares de explotación sino también a otros miembros de la familia. Esta modalidad de trabajo agrario, más intensa cuanto más pequeña es la explotación, alcanza los valores más altos en el litoral, con mayores posibilidades de empleo en cualquier sector económico. Hacia el interior el fenómeno pierde intensidad.

\section{RÉSUMÉ}

Pendant les derniéres annés, l'agriculture à temps partiel a acquis une importante augmentation au Pais Valencià, au point même que la terre a laissé d'étre la principale source de recettes chez beaucoups de foyers, elle acquière de plus en plus le caractère de complement dans les économies familiales.

La pluriactivité ne touchent seulement pas au titulaires d'explotation mais aussi à d'autres membres de la famille. Cette modalité de travail agricole, plus intense quand les explotations sont plus reduites, atteint les plus hautes valeurs dans le littoral, avec plus de possibilités d'emploi chez n'importe quel autre secteur économique. Vers les zones plus à l’interieur le phénoméne perd son intensité.

En todas las regiones españolas, y, en particular, en el País Valencià, numerosas familias campesinas cuentan con explotaciones de las que, por su dimensión, orientación productiva, etc., no pueden obtener los recursos que les permitan 
cubrir sus múltiples necesidades. La penuria de las rentas agrarias, el deseo de lograr un mayor nivel de vida, empuja al empresario agrario a simultanear dos actividades a la vez: el trabajo en la explotación familiar y otra actividad externa, que desempeña en la industria, en los servicios, o en el mismo sector agrario como jornalero. Independientemente de que el titular de la explotación trabaje fuera o lo haga sólo en las tierras propias, otros miembros de la familia, la esp osa y/o los hijos, pueden tener su ocupación principal en actividades externas, ap ortando sus salarios al conjunto de las rentas familiares. Jefe y familia son agricultores, pero con una diferencia, no son sólo agricultores; sostienen sus explotaciones, pero dividen su tiempo de trabajo entre ésta y otras actividades. La pluriactividad del jefe y/o de la familia permite la obtención de unos ingresos complementarios que no sólo contribuyen a mejorar las condiciones de vida, sino que en muchos casos permite el mantenimiento de la explotación.

A la práctica de esta doble actividad se le ha venido en llamar agricultura a tiempo parcial. En los últimos años, el fenómeno está adquiriendo una importancia creciente en los países fuertemente industrializados, lo que se manifiesta en el aumento del número de agricultores que la practican, alrededor del $50 \%$ de los empresarios agrarios obtienen más de la mitad de sus rentas en actividades que realizan fuera de la explotación; en el Estado español, el 66\% de los jefes tienen otra ocupación principal, y en el País Valencià son más del $80 \%$ los empresarios alternantes. Pese a la importancia que alcanz a la agricultura a tiempo parcial, aunque sólo sea por la mera extensión cuantitativa, son escasas las obras que abordan el fenómeno de una forma directa.

Para los estudiosos de las estructuras agrarias, la fragmentación de las explotaciones, y su acusado minifundismo, han contribuido a fomentar la agricultura a tiempo parcial ${ }^{1}$. A consecuencia de la excesiva fragmentación, muchos empresarios no obtienen de sus explotaciones una renta agrícola aceptable, p or lo que se ven obligados a completarla con el salario ganado por el trabajo externo ${ }^{2}$, de esta forma la agricultura a tiempo parcial adquiere el carácter de alternativa frente a la crisis de la pequeña explotación ${ }^{3}$. Sería la respuesta del agricultor ante la progresiva depreciación de sus rentas, lo que le empuja a buscar otros ingresos en actividades externas a la explotación ${ }^{4}$. Esta segunda ocupación puede efectuarla en la industria, los servicios o en el mismo sector agrario, como hacen muchos pequeños propietarios agrarios en comarcas naranjeras, donde la agricultura a tiempo parcial alcanza los valores más altos $^{5}$.

Entre los investigadores que han abordado el tema de la agricultura a tiempo parcial merece destacarse la obra del profesor Arnalte ${ }^{6}$, cuyo trabajo constituye el primer paso, serio e importante, que se da en España en esta dirección. En él analiza el proceso de salida de la población activa del sector agrario en seis municipios del regadío valenciano, tres en zona de huerta, y tres en la de naranjo. En este trabajo se demuestra que la agricultura a tiempo parcial depende fundamentalmente de la estructura agraria y de la disponibilidad de empleos alternativos, siendo los empresarios que cuentan con una menor dimensión quienes tendrán que buscar fuera de sus explotaciones otros ingresos que completen sus reducidas rentas agrarias. También se pone de manifiesto el papel del 
mercado de la tierra en la expansión de los empresarios hacia cultivos con escasas exigencias de trabajo, como el naranjo. En definitiva, el profesor Arnalte analiza las formas de agricultura a tiemp o parcial originadas al incidir el proceso de industrialización sobre determinados sistemas agrarios, destacando el carácter estable del fenómeno.

\section{Niveles de importancia de la agricultura a tiempo parcial}

La Encuesta del I.N.E., de $1965^{7}$, que utilizaba como criterio los ingresos que las familias camp esinas obtenían fuera de la explotación, puso de relieve la extraordinaria importancia de la agricultura a tiempo parcial en el País Valencià. En efecto, en «Levante» casi el 47\% de los ingresos de los hogares camp esinos eran resultado del trabajo realizado fuera de la explotación, situándose, en orden de importancia, sólo por detrás de Euskadi, donde los ingresos externos llegaban a representar la mitad del total de las rentas familiares.

A comienzos de los años setenta, según recoge el Censo Agrario de 1972, el 66\%, de los titulares de explotación tenían «ocup ación princip al no agraria». Diez años más tarde, alrededor del 85\% de los miembros de la familia no dedicaban la mayor parte de su tiempo laboral a la explotación. El último trabajo que aborda el fenómeno de la agricultura a tiempo parcial en nuestro país ${ }^{8}$, ha confirmado la importancia que esta modalidad de explotación alcanza en tierras valencianas.

Por todo ello, consideramos interesante analizar el fenómeno en nuestra región. Debemos subray ar que la información de que disponemos, el Censo Agrario, al utilizar el criterio tiempo, y no el de las rentas, limita las posibilidades de análisis. Así, puede haber campesinos que trabajando la may or parte del tiempo en la explotación, obtengan más de la mitad de sus rentas fuera de ella; éstos, según las directrices comunitarias, también deberían ser considerados como agricultores a tiempo parcial.

Dimensión de la explotación y dedicación de los campesinos

Con los resultados correspondientes al Censo Agrario de 1982 se ha elaborado la figura 1, donde aparecen empresarios (a la izquierda) y ayudas familiares (a la derecha), distribuidos por tamaños de explotación, distinguiendo en cada grupo a los agricultores a tiempo parcial de quienes tienen su ocupación principal en la explotación.

La may or parte de las explotaciones, en especial las más pequeñas, están dirigidas por empresarios que tienen una ocupación ajena a las tareas de la explotación, y, como ellos, son pocas los ayudas familiares que se dedican de manera exclusiva a las actividades de la exp lotación. En consecuencia, la escasa dimensión es una de las causas por las que los miembros de la familia campesina deben simultanear el trabajo dentro y fuera de la explotación.

En dimensiones superiores a $5 \mathrm{Ha}$ disminuye la importancia de la alternancia, sobre todo en el grupo de empresarios con explotaciones de más de $10 \mathrm{Ha}$. Aunque lo reducido de los efectivos no permite apreciarlo con claridad, en 


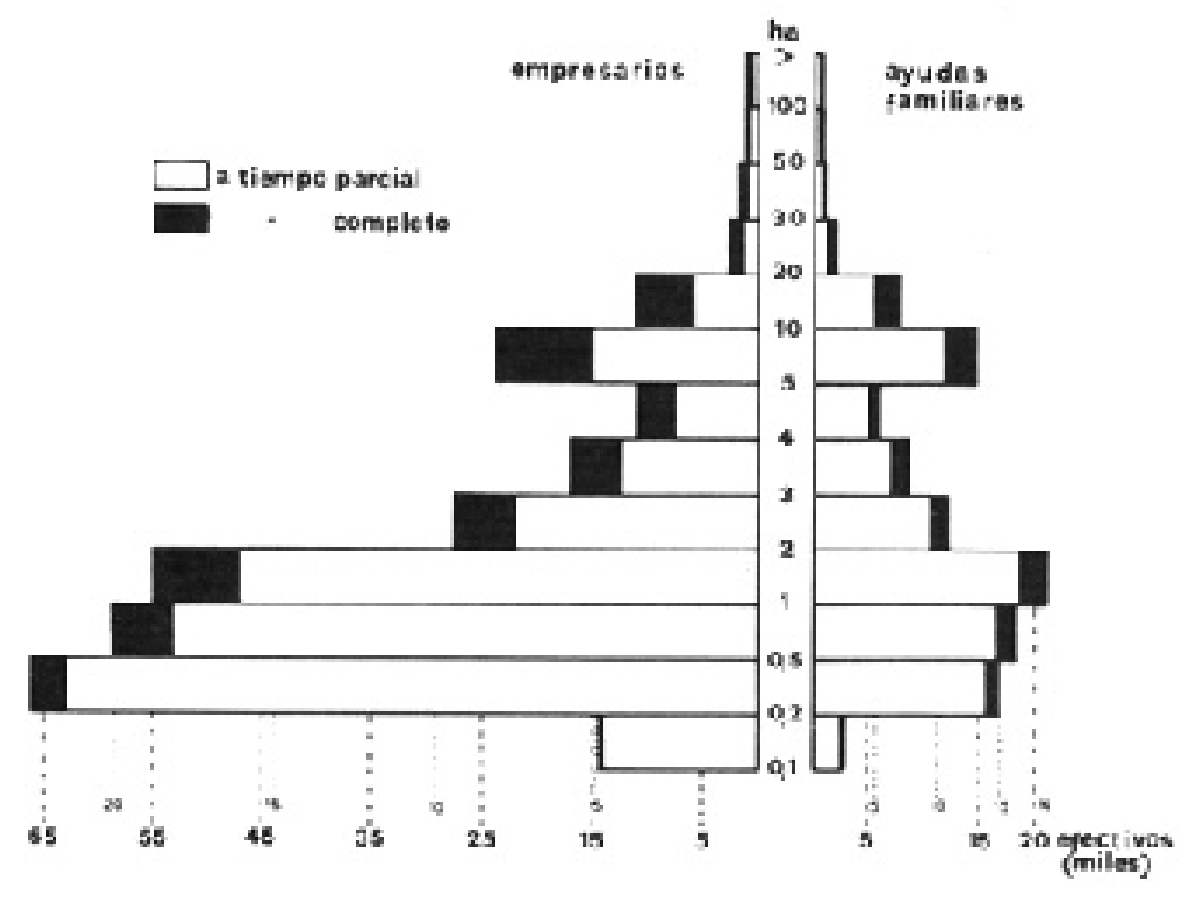

Figura 1. País Valencià. 1982. Empresarios y ayudas familiares distribuidos por tamaños de explotación. Porcentajes con respecto a los efectivos de cada grupo.

explotaciones con más de $50 \mathrm{Ha}$, como han observado otros autores ${ }^{9}$, hay una gran proporción de empresarios sin dedicación principal en la explotación, la participación de estos jefes debe ser más que nada de dirección ${ }^{10}$. Para analizar las causas de la menor dedicación de los camp esinos con más de $50 \mathrm{Ha}$, se deberían conocer las actividades que desemp eñan fuera de la explotación, a lo que nos referiremos más adelante, no sin ciertas limitaciones, ya que la información censal en lo referente al tipo de ocupación principal es muy pobre.

En los últimos años se ha producido una considerable expansión del fenómeno. Lo podemos ap reciar de forma clara en la figura 2, en la que se compara la distribución de empresarios por tamaños de explotación en 1972 y $1982^{11}$.

Como en España ${ }^{12}$, los empresarios con ocupación principal fuera de la explotación han aumentado en todas las categorías dimensionales, pero esp ecialmente en las más modestas. En 1982, los alternantes en explotaciones hasta media hectárea representaban más de la cuarta parte del empresariado agrario. Por 


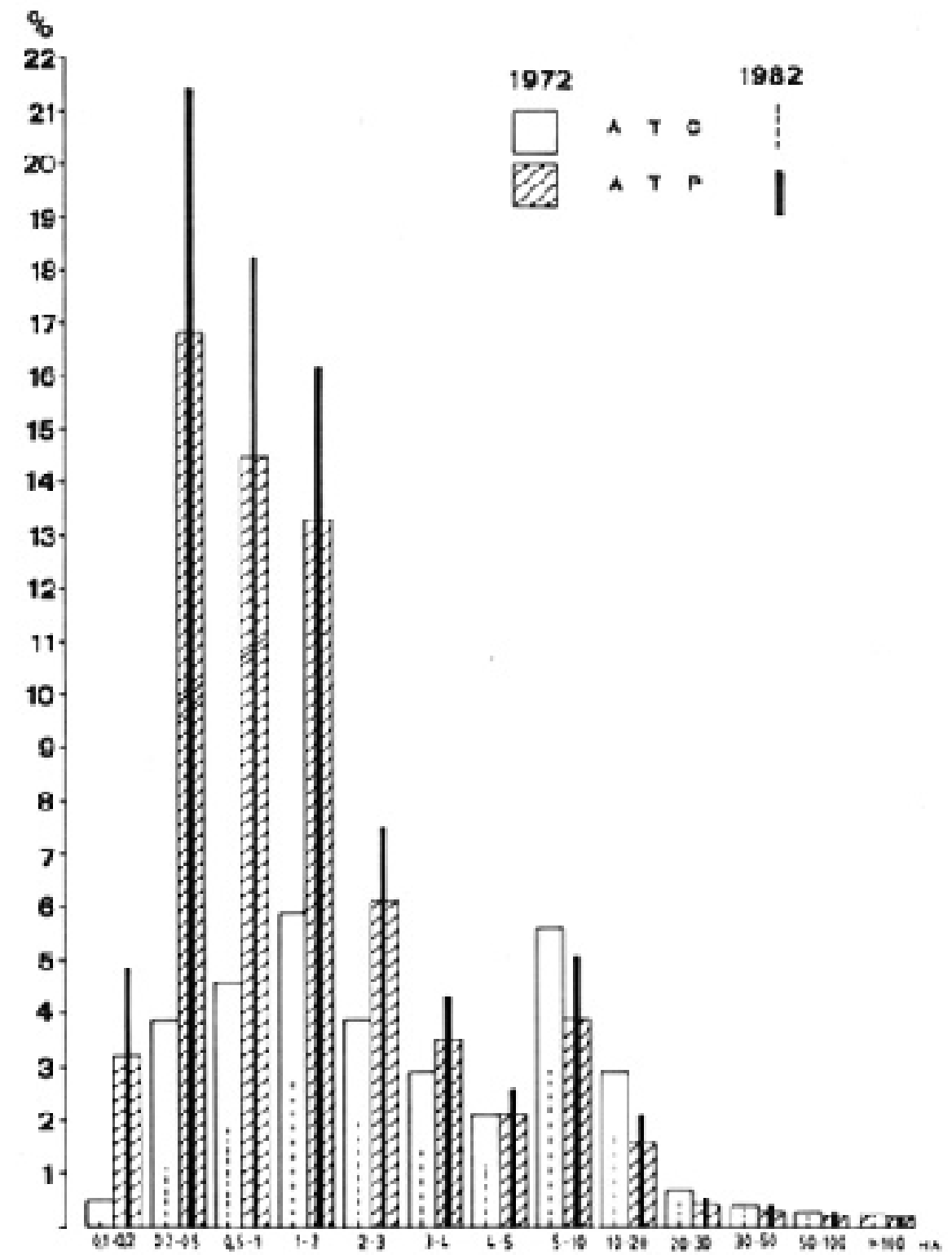

FIGURA 2. País Valencià. Jefes de explotación por tamaños de explotación, en 1972 y 1982. 
lo que resp ecta a los emp resarios que declararon dedicar la may or parte de su tiempo de trabajo a la explotación, se han reducido en todos los tamaños, han pasado a engrosar los efectivos de los alternantes. El trasvase ha sido tanto más acusado cuanto menor es la dimensión de la explotación.

En definitiva, puede afirmarse que buena parte de las explotaciones que eran viables en 1972 han dejado de serlo diez años más tarde, ya que sus jefes comparten la dirección de la explotación con una actividad externa. Si bien, el incremento del número de agricultores a tiempo parcial debe relacionarse con la aparición de «nuevos empresarios agrarios», que, trabajando en el exterior, en el momento de adquirir la tierra -por compra o por herencia-, han hecho queexplotaciones a tiemp o comp leto, porque su titular dedicaba la may or parte del tiempo a la explotación, se hay an convertido en explotaciones a tiempo parcial; es decir, algunos titulares habrán adquirido la condición de empresarios «a posteriori» ${ }^{13}$.

\section{Ocupación principal de los campesinos}

En el País Valencià, como se puede apreciar en la figura 1, hay una extraordinaria diferencia entre el número de empresarios agrarios (292.600) y el de los ay udas familiares (113.594), que, con mayor o menor dedicación, intervienen en las tareas de la explotación, prueba evidente de que el trabajo recae fundamentalmente sobre el titular. Hecha esta observación, y atendiendo a la distribución porcentual de los dos colectivos, apenas hay diferencias -dignas de mención- entre el tipo de ocupación principal de empresarios y ayudas, a no ser la menor dedicación de éstos a las actividades de la explotación, y su mayor participación en actividades remuneradas externas.

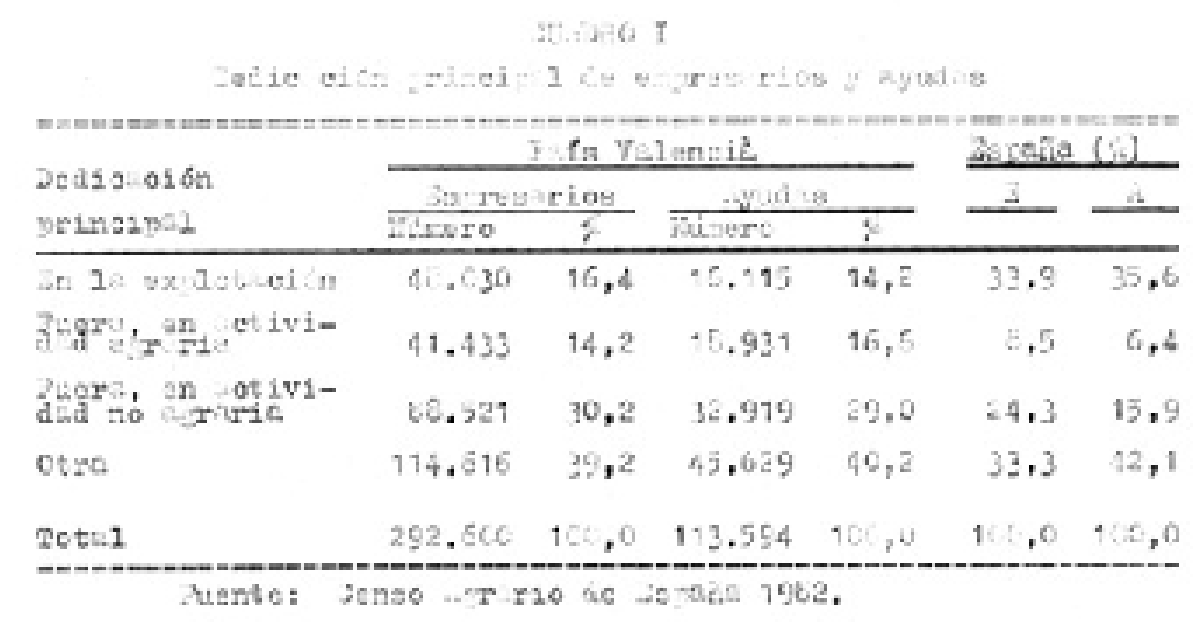


La necesidad de obtener otras fuentes de ingresos no afecta sólo al titular, sino también a la esp osa y a los hijos. Entre los miembros de la familia campesina predominan quienes además de trabajar en la explotación cuentan con un empleo externo (el 44’4\% de los jefes, y el 45’6\% de los ayudas). La mayoría trabajan en actividades no agrarias; si bien, el porcentaje de empresarios y ayudas cuy a ocupación principal es la de hacer jornales dentro del mismo sector agrario, uno de cada tres individuos «activos», no es nada despreciable. En el País Valencià, como en Andalucía, Extremadura o Murcia, el trabajo asalariado agrícola constituye una importante fuente de empleo para los componentes del hogar campesino. Alrededor del $40 \%$ tienen «otra» ocupación principal, no dedican la mayor parte de su tiempo a la explotación, ni desempeñan actividades remuneradas. El resto, entorno al 15\%, deben ser considerados como agricultores a tiempo completo.

Esta distribución difiere notablemente de la que empresarios y ay udas muestran para el conjunto del Estado, donde uno de cada tres camp esinos trabaja la may or parte de su tiemp o en la explotación. La menor proporción de agricultores valencianos a pleno tiempo, se debe a las op ortunidades que tienen para dobleemplearse en la industria, en los servicios y en la misma agricultura. Es en el sector agrario, como generador de empleo asalariado, donde radica una de las princip ales diferencias entre empresarios y ayudas de uno y otro sitio; en el País Valencià los porcentajes de jornaleros dup lican a los del Estado, en relación con el minifundismo de nuestras exp lotaciones y con el monocultivo de cítricos, cuy o tratamiento y recolección exigen abundante mano de obra.

También se pueden destacar diferencias provinciales, que, aunque mínimas, no dejan de ser significativas, según se recoge en el cuadro II.

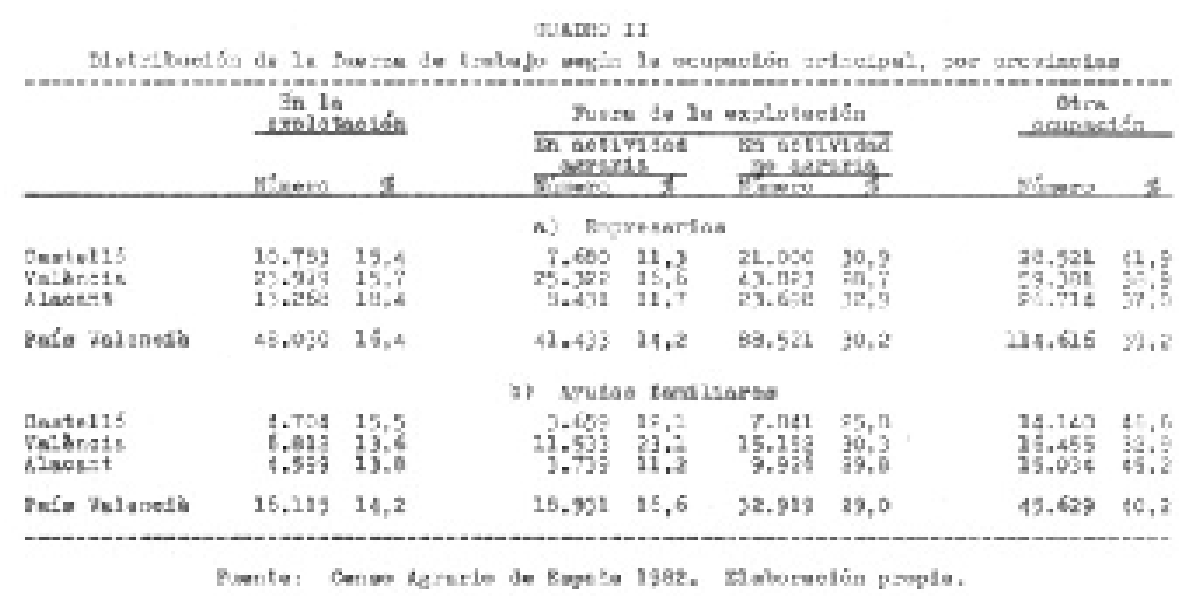

En Alacant una mayor proporción de empresarios (el 18’4\%) obtiene de sus explotaciones las rentas necesarias para poder vivir. En València destaca la 
may or proporción de miembros de la familia campesina ocupados en actividades externas (el 45 ’3\% de los jefes, y el 53’4\% de los ay udas), siendo la provincia donde las actividades agrarias ofrecen mayores posibilidades de empleo. Por su parte, en Alacant, con una agricultura menos rica, son las actividades industriales: calzado, juguete, turrón, etc., y de servicios: turismo-hostelería, las que emplean a una may or prop orción de titulares de explotación. Castelló se encontraría en una posición intermedia entre las otras dos provincias valencianas, registra el porcentaje más bajo de empresarios y ayudas con actividad remunerada externa, siendo destacable el elevado porcentaje de quienes tienen «otra» ocupación principal (el 41'9\% de los jefes, y el 46’6\% de los ayudas), lo que debe relacionarse, al menos en parte, con el mayor grado de envejecimiento.

\section{Tipo de ocupación y dimensión de las explotaciones}

En la figura 3 hemos representado la distribución de empresarios y ayudas, según la ocupación principal, por categorías de explotación, lo que nos permitirá relacionar el tipo de actividad con la dimensión.

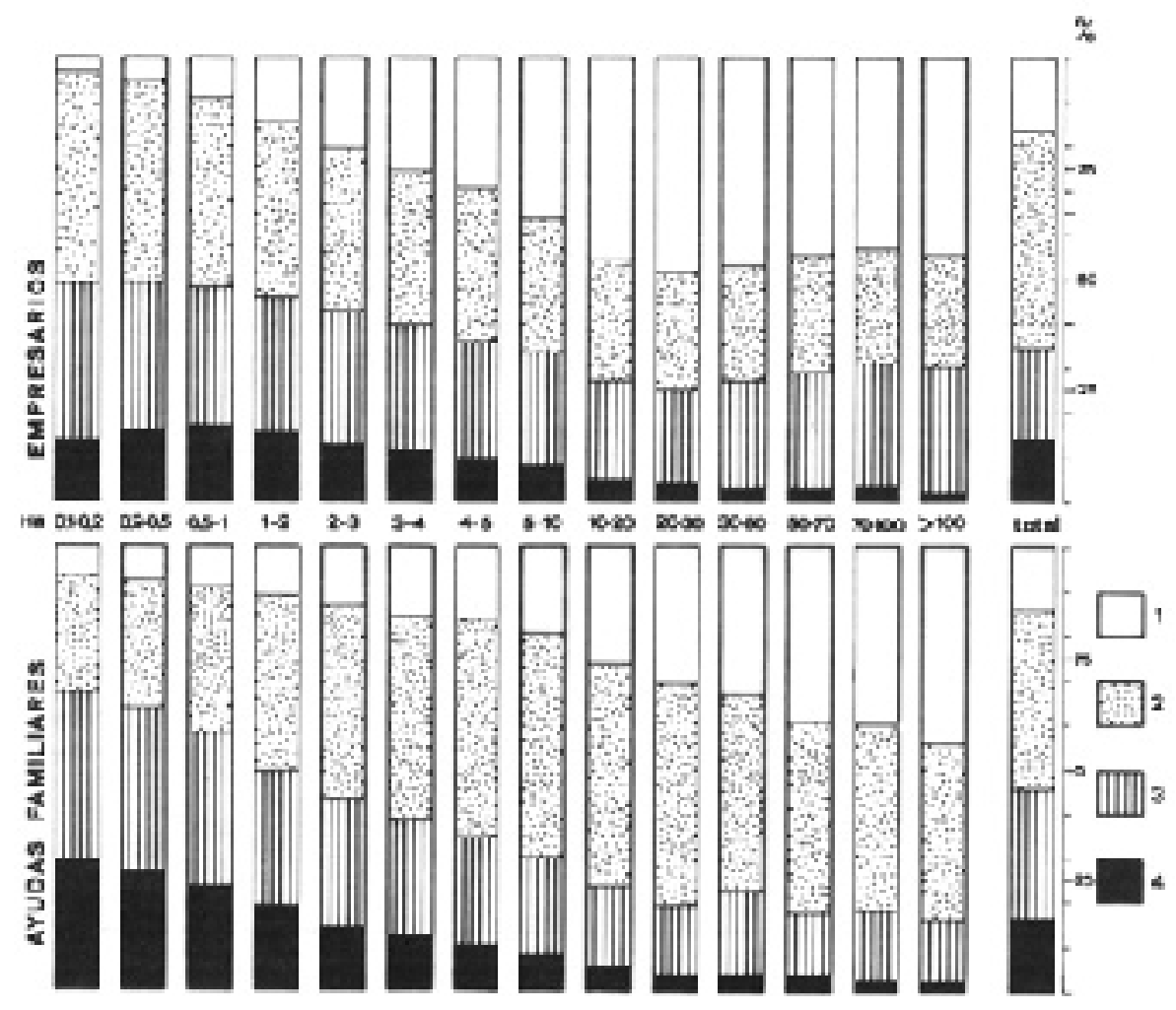

Figura 3. País Valencià. 1982. Valores porcentual es de la fuerza de trabajo familiar, por tamaños de explotación. Ocupación principal, 1, en la explotación; 2, «otra»; 3, fuera de la explotación en actividad no agraria; 4, fuera de la explotación en actividad agraria. 
Los resultados obtenidos indican que los campesinos dobleempleados predominan de forma absoluta en las exp lotaciones más pequeñas, en las inferiores a 1 Ha trabajan en el exterior la mitad de los jefes y alrededor del $60 \%$ de los ayudas familiares. A medida que aumenta el tamaño de la explotación disminuye progresivamente el porcentaje de campesinos alternantes, y aumenta rápidamente el de quienes dedican la mayor parte de su tiempo al cuidado de las tierras familiares, en especial por encima de las $10 \mathrm{Ha}$. Lo que viene a significar que a partir de cierto tamaño aparece un buen número de empresas que absorben todos los esfuerzos del camp esino, en particular del titular.

Tal como queda reflejado en el gráfico, en todos los tamaños de exp lotación la pluriactividad se ejerce sobre todo en empleos no agrarios. Sin embargo, en unidades de explotación inferiores a $4 \mathrm{Ha}$ los jornaleros agrarios tienen cierta relevancia; por encima de este umbral hay muy pocos campesinos que además de atender a sus tierras dediquen la may or parte de su tiempo a trabajar en explotaciones ajenas. Así pues, en el País Valencià, los titulares y ay udas familiares que trabajan de asalariados agrícolas poseen pequeñas parcelas; sin duda, obtendrán la may or p arte de sus rentas en los jornales, algunos deben ser jornaleros sin tierra que han llegado a la propiedad con gran esfuerzo de ahorro. En cualquier caso, se trata de pequeños propietarios jornaleros agrarios, su condición más que de prop ietarios es la de jornaleros, ya que, como ha señalado Josep Vicent Marqués ${ }^{14}$, su vida está presidida por la búsqueda del jornal, trabajando sus tierras en ausencia de mejor ocupación por cuenta ajena.

Como los anteriores, los campesinos con ocupación principal en actividades no agrarias logran una may or representación en explotaciones de escasa dimensión. A este grupo pertenecen aquellos que, deseando aumentar sus dep reciadas rentas agrarias, abandonan la explotación como ocupación princip al para trabajar en la industria o en los servicios; y -el caso contrario- quienes acceden a la propiedad después de haberse iniciado en la actividad externa. A diferencia de los camp esinos jornaleros, que de forma progresiva disminuyen su importancia relativa a medida que aumenta el tamaño de la explotación, los activos no agrarios, tras un ligero descenso, vuelven a aumentar su participación en explotaciones con más de 30 Ha. Quizás en estas dimensiones se encuentren los empresarios para los que, como dice el profesor Gozálvez ${ }^{15}$, «la tierra es sólo una consecuencia de inversiones en tierras», se trata de clases medias y profesionales urbanos ${ }^{16}$.

Si separamos los activos agrarios de los activos no agrarios, el mayor contingente de empresarios y ayudas familiares corresponde a quienes tienen «otra ocupación» principal. Mientras entre los empresarios esta situación predominaen explotaciones inferiores a $5 \mathrm{Ha}$, p ara, a partir de aquí, ceder ante la may or p rop orción de agricultores a tiemp o completo; en los ayudas familiares, es, precisamente, en las explotaciones más pequeñas donde tiene menor relevancia, mientras la aumentan en explotaciones mayores, al tiempo que lo hacen quienes dedican la may or parte de su tiempo de trabajo a la explotación. Poco se puede decir acerca de este grupo, pues el término «otra ocupación» es muy abstracto, incluye una gran variedad de categorías ${ }^{17}$. En nuestra opinión, debe estar integrado principalmente por jubilados y amas de casa. 


\section{Distribución espacial de la agricultura a tiempo parcial en el País Valencià}

Para el análisis de la agricultura a tiempo parcial hemos seguido la comarcalización agraria realizada, y publicada, por la Secretaría General Técnica del Ministerio de Agricultura, Pesca y Alimentación. Aunque discrepamos de esta división comarcal, un tanto alejada de criterios estrictamente geográficos, su elección obedece al hecho de que el Censo Agrario ofrece información más detallada p ara las comarcas ${ }^{18}$ que para los municipios. En este sentido, conviene destacar que la utilización de otra división comarcal, agrupando los datos municipales, no nos hubiese permitido distinguir a los alternantes jornaleros agrarios de quienes tienen su ocupación principal en la explotación, categorías que en la información municipal aparecen unidas en el grupo «ocupación principal agraria», mientras en las comarcas están claramente diferenciadas.

\section{Una primera aproximación al fenómeno}

En primer lugar, es apropiado hacer una valoración general de la agricultura a tiempo parcial. Como queda reflejado en la figura 4, el fenómeno de la alternancia no alcanza la misma intensidad a lo largo del País Valencià, además en la práctica totalidad del territorio la complementariedad entre las tareas de la explotación y otras actividades alcanza mayor imp ortancia relativa entre los ayudas familiares, a pesar de que -como se ha indicado- para el conjunto del País las diferencias entre uno y otro colectivo son mínimas. Esto es así porque en el caso de los titulares de explotación el porcentaje de alternantes es resultado de fuertes contrastes entre unas comarcas y otras, mientras que entre los ayudas familiares los valores comarcales son menos divergentes.

En el mapa, sobre todo en el de los jefes, aparece bien delimitada un área de menor implantación del fenómeno, interior de la provincia de Valencia y comarcas más septentrionales de la de Castelló. En el litoral, los niveles de importancia son mayores.

Estos resultados parecen demostrar la estrecha relación entre el grado de industrialización-urbanización y las posibilidades de alternancia. Sin embargo, la oscilación del indicador entre una comarca fuertemente industrializada, «la Huerta de Valencia», y otra eminentemente agraria, la de «Gandía», con mayor proporción de alternantes en esta última, pone de manifiesto que la agricultura a tiemp o parcial no se puede explicar sólo en función de la industrialización, también responde a factores agrarios, estructura de las explotaciones, tipo de cultivo, posibilidades de empleo dentro del mismo sector agrario, etc.

La importancia de la agricultura a tiempo parcial en el regadío, como han señalado otros autores ${ }^{19}$, se debe en gran parte a la presencia de numerosos pequeños empresarios que trabajan de jornaleros. Por esta razón, no podemos admitir la afirmación de que «a nivel comarcal, lo que determina la mayor o menor importancia de la agricultura como ocupación principal es, sin duda, la existencia de una industrialización y de una urbanización poco o muy acusada, respectivamente» ${ }^{20}$. Las actividades no agrarias, con ser importantes no son las únicas que desempeñan los alternantes, sobre todo en el regadío litoral. En 

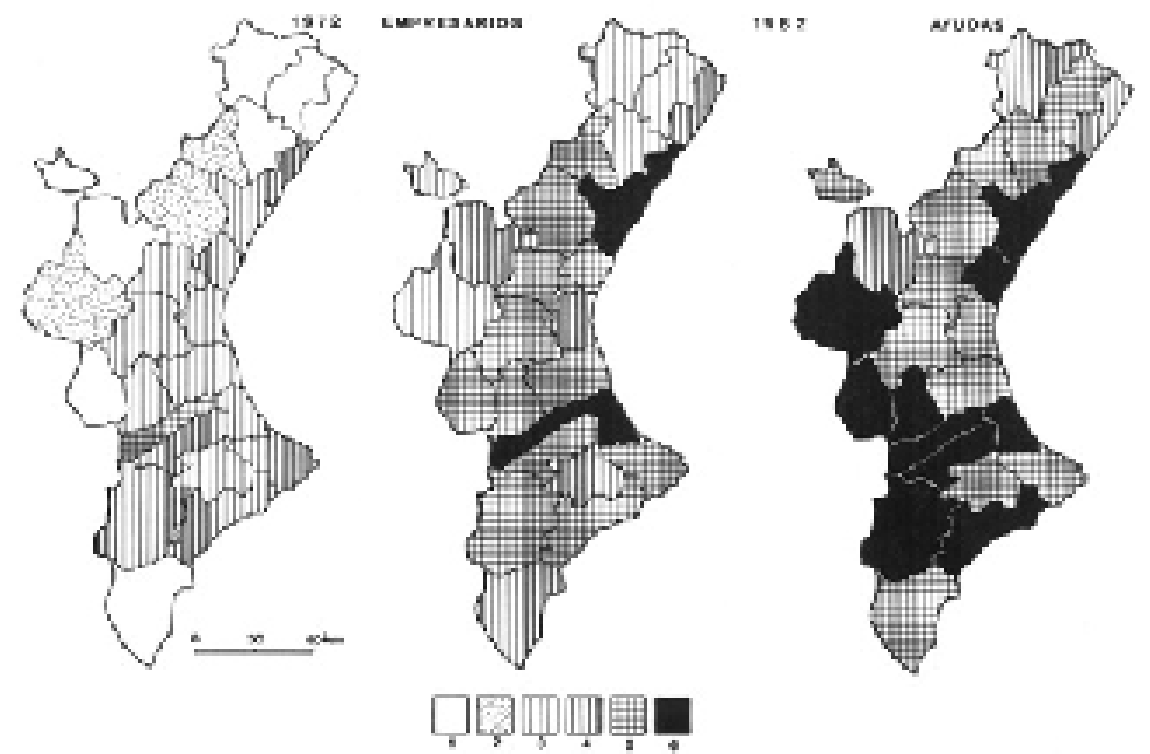

FIGURA 4. Proporción de campesinos alternantes en las comarcas valencianas. 1, menos del 50\%; 2, 50-60; 3, 61-70; 4, 71-80; 5, 81-90; 6, más del 90\%. 
algunas comarcas, el sector agrícola oferta más empleo que las actividades industriales o de servicio, principalmente entre los ayudas familiares.

El fenómeno de la agricultura a tiempo parcial es importante en todas las comarcas, si bien predomina fundamentalmente en el regadío y en áreas de secano con fuerte implantación industrial ${ }^{21}$. En el interior, la relación entre el grado de industrialización y el indicador de alternancia se puede observar en la "Costera de Játiva», comarca con important e actividad económica no agraria. En líneas generales, se aprecia que las comarcas costeras y contiguas tienen una mayor proporción de empresarios alternantes. A medida que nos dirigimos hacia el interior, especialmente en el norte, el fenómeno pierde intensidad. Con todo, en los últimos diez años, entre 1972 y 1982, todas las comarcas registran un notable incremento de esta modalidad de explotación.

Como se ha dicho, los indicadores del fenómeno son may ores entre los ayudas familiares, con la particularidad de que algunos de los valores más altos se registran en comarcas con menor proporción de empresarios a tiempo parcial. Debemos tener en cuenta lo reducido de los efectivos; si bien, se podría argüir, en una primera evaluación, que la alternancia de los ayudas permite a algunos empresarios comportarse como agricultores a tiempo completo.

\section{Agricultura a tiempo parcial y pequeña explotación}

Como ya señalara Pérez Casado hace unos veinte años, el País Valencià se caracteriza por la existencia de un elevado número de explotaciones pequeñas o muy pequeñas ${ }^{22}$. Minifundismo que se ha acentuado con el transcurso del tiempo, a tal punto que en la actualidad (1982), casi la mitad de las explotaciones no alcanzan la hectárea de superficie agrícola utilizada ${ }^{23}$; la reducida dimensión de las explotaciones es más acentuada en el litoral (fig. 5). No vamos a exponer aquí los motivos de la extraordinaria fragmentación del terrazgo valenciano, de lo que se han ocupado otros autores ${ }^{24}$, lo que haremos será observar si existe, o no, relación entre la agricultura a tiemp o parcial y la dimensión de la exp lotación.

Tal como hemos visto, en las pequeñas explotaciones hay un predominio absoluto de camp esinos cuy a ocupación principal no son las tareas de la explotación familiar. Si se compara el map a de la figura 4 (jefes) con el de la figura 5, se puede afirmar que la agricultura a tiempo parcial es más intensa en comarcas con una may or proporción de explotaciones inferiores a 1 Ha, como ocurre en la Plana y en todo el litoral de la provincia de València. En las comarcas alicantinas las explotaciones modestas representan porcentajes semejantes al del conjunto regional, también hay una alta proporción de alternantes.

Las pequeñas explotaciones pierden importancia a medida que nos dirigimos hacia el interior, y, sobre todo, hacia el norte del País, coincidiendo con esta distribución una menor intensidad del fenómeno. Con todo, aunque el fraccionamiento de la tierra en las comarcas del interior no sea tan significativo, no por ello deja de ser importante la práctica de la agricultura a tiemp o parcial, tal como indican los valores registrados.

En definitiva, la mayor proporción de empresarios a tiempo parcial se da en 


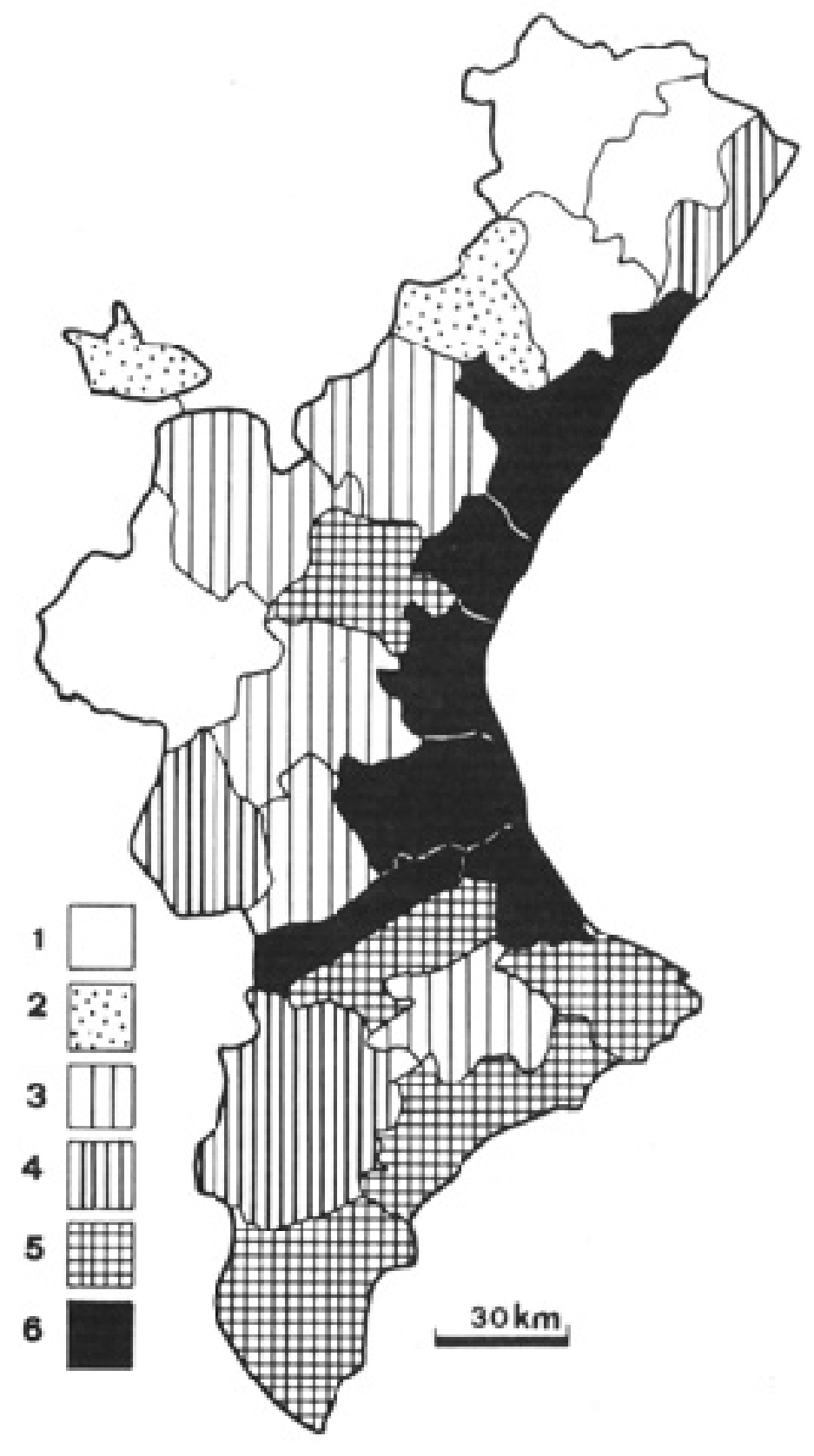

FIGURA 5. País Valencià. 1982 . Imp ortancia relativa de las explotaciones inferiores a 1 Ha de superficie agrícola utilizada. 1 , menos del 10\%; 2, 10-20; 3, 21-30; 4, 31-40; 5, 41-50; 6, más del 50\%. 
comarcas con may or predominio de explotaciones pequeñas. La dificultad de obtener unas rentas suficientes, dada la escasa dimensión, es una de las causas por las que el campesino alterna el trabajo dentro y fuera de la explotación.

Si esta relación parece clara en los empresarios, no lo es tanto en el caso de los ayudas familiares. Entre los miembros de la familia campesina hay una may or dedicación relativa a tareas no relacionadas con la explotación familiar en una extensa zona del interior de las provincias de València y Castelló, donde es baja la prop orción de explotaciones pequeñas. Esta situación podría relacionarse, quizás, con las características agrícolas, poco exigentes en trabajo, que sería aportado fundamentalmente por el titular; o, probablemente, esté en relación con la presencia de un buen número de ayudas familiares con «otra» ocupación, esp osas del empresario, amas de casa, o jubilados, en relación con el fuerte carácter emigratorio de estas comarcas ${ }^{25}$. Sea como fuere, debemos recordar que los resultados corresp onden a unos efectivos muy menguados.

\section{Distribución comarcal de los campesinos, según su ocupación principal}

Con la información comarcal facilitada por el Censo Agrario de 1982 hemos confeccionado el mapa de la figura 6, en el que, con semicuadrados proporcionales al número de campesinos, se representa a los empresarios (semicuadro inferior) y a los ayudas familiares (semicuadro superior), distinguiendo a los que tienen su ocupación principal en la explotación de los que la tienen fuera de ella, en actividad agraria y no agraria, y a quienes declararon tener «otra» ocupación principal.

El análisis de la distribución de los campesinos nos ha permitido caracterizar las siguientes áreas en función de la may or o menor importancia de cada categoría ocup acional ${ }^{26}$.

\section{Un interior con menores niveles de agricultura a tiempo parcial}

En las comarcas del interior, con escasa base industrial, alejadas de los centros industriales, con predominio de las pequeñas explotaciones de secano, y un poco más grandes en las comarcas septentrionales, un may or porcentaje de emp resarios debe conformarse con los reducidos ingresos procedentes de su explotación. Las zonas de menor implantación del fenómeno se localizan en la mitad norte de la provincia de Castelló, en el Alto y Bajo Maestrazgo, en los Llanos Centrales, donde los empresarios alternantes no superan el 70\%, y en el interior de la de València, en Requena-Utiel, donde superan ligeramente el 60\%. Con porcentajes semejantes destacan también el Alto Turia, el Rincón de Ademúz o la Montaña.

Mientras buena parte de los empresarios en comarcas del interior dedican todos sus esfuerzos a la explotación, hay pocos ayudas familiares que se dediquen de forma exclusiva a actividades agrarias propias. En esta área, la mayoría tienen «otra» ocupación principal, serán amas de casa o padres, ya jubilados, del titular, que con sus pensiones ap ortarán unos ingresos complementarios a las rentas familiares, permitiendo, en algunos casos, la existencia de empresarios a 


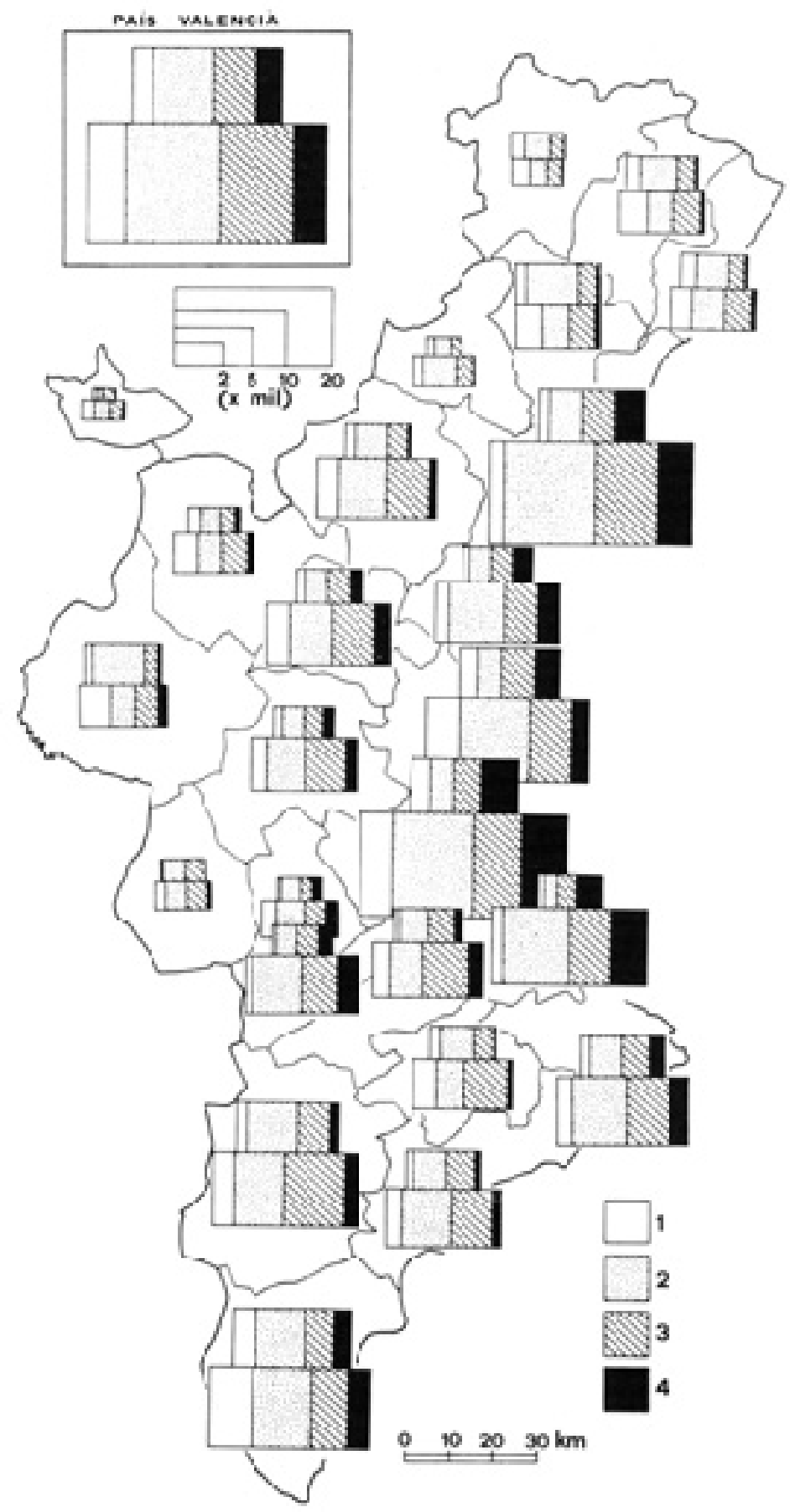

Figura 6. País Valencià. 1982. Distribución espacial de la fuerza de trabajo familiar. Tipo de ocupación principal: 1, en la explotación; 2, «otra»; 3, fuera de la explotación en actividad no agraria; 4, fuera de la explotación en actividad agraria. Semicuadro inferior, empresarios; semicuadro superior, ayudas familiares. 
tiemp o completo. Otros trabajan fundamentalmente en actividades no agrarias, con todo los valores son poco significativos dado lo reducido de los efectivos humanos.

Desde fecha relativamente reciente, la instalación de fábricas en medio rural ha contribuido a la proletarización del campesinado sin que necesariamente tenga que abandonar el pueblo, lo que constituye uno de los aspectos más característicos de los cambios que están transformando a la comunidad rural ${ }^{28}$, convirtiéndose en agricultores durante unos días al año, o los fines de semana. De esta forma la tierra ha dejado de ser la principal fuente de ingresos en muchos hogares, adquiriendo cada vez más el carácter de complementariedad.

2. Unas áreas hortícolas donde las explotaciones a tiempo completo tienen cierta entidad

Si la proporción de explotaciones a tiempo completo es relativamente elevada en las comarcas del interior, no lo es menos en zonas de características agrícolas bien distintas, como la Huerta de Valencia, la comarca Meridional o el Litoral Norte.

En estas áreas, las explotaciones -la may oría de dimensiones muy pequeñas- absorben más de la mitad del tiemp o de trabajo de entre la cuarta y la quinta parte de los titulares y ayudas familiares. Sin duda, en estas comarcas el cultivo intensivo de las huertas, con ocupación continua, y el naranjal, contribuy en a que el grupo de campesinos con ocupación principal en su exp lotación sea francamente imp ortante, pese al fraccionamiento de la propiedad y el desarrollo de la industria, que contribuy en a crear el ambiente propicio para la práctica de la alternancia.

Para muchos el trabajo como jornaleros en el mismo sector agrario constituye la actividad principal, lo que ha sido una práctica habitual entre los pequeños propietarios, que cada vez más prefieren completar sus ingresos con una actividad no agrícola ${ }^{29}$. La práctica de la alternancia en el mismo sector agrario debe relacionarse con las diferencias entre la pequeña y mediana explotación, y con el tipo de cultivo que requiere una serie de trabajos que deben hacerse en plazos de tiempo muy limitado. La agricultura a tiempo parcial de los jornaleros ha sido destacada en la Vega Baja ${ }^{30}$.

En 1982, la actividad en explotaciones ajenas daba trabajo a un mayor porcentaje de ayudas familiares que de titulares de explotación. En el Litoral Norte, los valores reflejados por las estadísticas deben ser sensiblemente inferiores a los reales, pues son muchas las mujeres «que se dedican a la recogida de naranjas en la larga temporada de noviembre a mayo..., la mayoría no declara esta actividad al ser de carácter temporero» ${ }^{31}$, alegando como ocupación sus labores, por lo que se incluirán en el grup o de «otra» ocupación principal, al que pertenecen la mitad de los ayudas, y el $40 \%$ de los titulares.

Para los ayudas familiares, la explotación reúne pocos atractivos; «los hijos se han alejado de la tierra y encuentran ocupaciones mejor remuneradas y más cómodas en la industria 0 en los servicios» ${ }^{32}$. Algunos han abandonado definitivamente el hogar paterno, han emigrado o se han emancipado, otros continúan 
viviendo con sus padres, pero trabajan la may or parte de su tiempo en actividades externas. De manera que para un futuro no muy lejano cabe esperar una intensificación del fenómeno de la alternancia, ya que cuando los hijos hereden la tierra, los que viven dentro y fuera de la explotación, se convertirán en agricultores a tiemp o parcial.

3. Comarcas con alta proporción de alternantes, de los que muchos se ocupan en actividades agrarias

En el litoral los niveles de imp ortancia del fenómeno son may ores, los altos porcentajes registrados en la Costera, Gandía, la Plana, Sagunt o el Marquesado, indican hasta qué punto es ya casi una misma cosa hablar de agricultura y agricultura a tiempo parcial.

En estas comarcas, al igual que en las Riberas del Júcar, es donde alcanzan una mayor imp ortancia relativa los miembros de la familia con ocupación principal en actividades agrarias fuera de la explotación. Con la particularidad de que el trabajo asalariado en la agricultura emplea a un may or porcentaje de ayudas familiares que de jefes.

La alta proporción de jornaleros agrarios, que en algunos casos equivale a uno de cada cuatro titulares de explotación, y a más de un tercio de los ayudas familiares, debe relacionarse con las reducidas dimensiones de la may or parte de las explotaciones y con las posibilidades que ofrece la recolección de la naranja y de productos hortícolas. «Las escasas dimensiones de las propias explotaciones revierten la necesidad de trabajar otras tierras de propiedad ajena» ${ }^{33}$. Además, se trata de comarcas con un imp ortante desarrollo industrial y de servicios, sectores en los que se emplean un buen número de campesinos.

En Gandía, la práctica de la alternancia por parte de los pequeños empresarios agrarios ya fue puesta de manifiesto por Fontavella en los años cincuenta: «en la huerta, salvo alguna finca grande..., el resto (de la tierra) está en manos de pequeños propietarios que algunas veces trabajan en otra actividad no agrícola..., algunos son gente de profesiones liberales y oficios administrativos..., que tienen pequeños huertos como quien posee participación en una pequeña empresa industrial..., otros son labradores que muchos días ganan su jornal trabajando para otro agricultor propietario con may or cantidad de tierra» ${ }^{34}$.

En el caso de las Riberas del Júcar, los productos hortícolas y los agrios permiten a un buen número de titulares de explotación y ayudas familiares trabajar como jornaleros, como ocurre en el municipio de Fortaleny, donde la recolección de la naranja -durante ocho o nueve meses- se convierte en la ocupación principal de muchas familias, «los pequeños y medianos empresarios adecuan el trabajo que realizan en sus tierras al ritmo seguido por la recolección de cítricos, que pasa a ser la principal fuente de ingresos familiares» ${ }^{35}$.

En Sagunt, como en la Plana, el cultivo del naranjo, la actividad industrial y el reducido tamaño de las explotaciones, crean las condiciones propicias por las que «muchos labradores tienen que complementar los rendimientos de sus pequeños campos trabajando a jornal en tareas agrícolas, o bien en el sector industrial 0 en el terciario..., es frecuente que estos trabajadores vayan a cuidar 
sus parcelas a la salida del trabajo» ${ }^{36}$. Es curioso destacar que en la comarca de Sagunt, pese al elevado índice de industrialización, el volumen de agricultores trabajando fuera de su explotación en actividad no agraria sea relativamente bajo (el 27\% de los empresarios y alrededor del 30\% de los ayudas familiares), uno de los más bajos registrados en todo el País Valencià.

Como se viene apreciando desde hace tiempo, la fragmentación de la propiedad, el deterioro de las rentas agrarias, el desarrollo del empleo industrial y de ciertos servicios, así como el cultivo de cítricos, han favorecido en el Marquesado que el pequeño explotador salga fuera en busca de otras fuentes de ingresos, atendiendo la explotación propia durante el tiemp o libre. El profesor Costa ha observado «la práctica de una agricultura a tiempo parcial aprovechando los fines de semana y las festividades, y realizando cuando se alarga el día las tareas más urgentes, durante la madrugada o tras el turno de trabajo» ${ }^{37}$.

En definitiva, en el regadío litoral el empleo fuera de la explotación familiar no sólo está originado por actividades industriales, tiene mucho que ver con la misma agricultura. Para la gran may oría de los pequeños propietarios de las comarcas naranjeras, la tierra realiza en gran medida la función que en otros sitios tiene la industria, proporciona ingresos en forma de jornales». Otros trabajan en actividades relacionadas con la agricultura (empleados del comercio de cítricos). Todo ello debido al grado de integración horizontal que se aprecia en la agricultura de regadío, de manera que quienes trabajan su explotación realizan diferentes tareas (poda, tratamientos, etc.) en explotaciones ajenas, bien como, asalariados, directamente, o bien en pequeñas emp resas de servicios, o, incluso, en actividades comerciales directamente relacionadas con la producción agraria, cooperativas exportadoras, etc.

\section{Comarcas con alta proporción de campesinos ocupados en actividades no agrarias}

Es en las comarcas con una may or tradición industrial o con instalaciones recientes, y con agricultura de secano, donde la ocupación principal en actividades no agrarias alcanza los porcentajes más altos. En el Vinalopó, la Montaña y los Valles de Albaida, los jefes de explotación que alternan la dirección de sus tierras con un trabajo en la industria o los servicios representan más del 40\%. Entre los ayudas familiares la proporción es sensiblemente inferior.

Las diferencias deben relacionarse con la más temprana incorporación del cabeza de familia al mercado de trabajo exterior. Si bien, en muchos municipios la participación de los ayudas en actividades no agrarias debe ser superior a la indicada por el Censo Agrario. Muchas mujeres que se consideran amas de casa, de profesión «sus labores», dedican buena parte de su tiempo a la administración del pequeño negocio familiar (carnicería, panadería, tienda de ropa, electrodomésticos, etc.), mientras el marido, que es quien figura al frente del negocio, se dedica realmente a la explotación ${ }^{40}$.

En los Valles de Albaida, como ha señalado Cucó en el caso del municipio de la Pobla del Duc, donde la mayor parte de la superficie labrada se dedica al cultivo de la uva de mesa, el encarecimiento de la mano de obra, la mecanización, 
el estancamiento relativo de los precios agrícolas, entre otros factores, han hecho «necesaria la búsqueda de otras fuentes de ingresos que ayuden a mantener el nuevo nivel de vida» ${ }^{41}$, los nuevos puestos de trabajo creados a partir de 1972 ó 1973 van a significar una fuente de ingresos complementarios.

En el Vinalopó el extraordinario desarrollo alcanzado por la industria del calzado, la cerámica o las industrias metálicas convierten la ocupación en actividades no agrarias en el sector rey como ofertador de trabajo a la may or parte de los jefes de explotación -41’2\%-. Esto, unido a la reducida dimensión de las explotaciones con aprovechamiento agrícola, vinculado al tradicional cultivo cerealístico o al monocultivo vitícola, hace que la may or parte del quehacer de los empresarios transcurra fuera de la explotación, empleándose sobre todo- en actividades industriales, mientras unos pocos -10'5\%- trabajan a jornal. El profesor Matarredona en un análisis sobre las estructuras agrarias del Alto Vinalopó ha observado que en los municipios pequeños y más agrarios es donde el fenómeno de la alternancia alcanza una menor intensidad, mientras en los más grandes e industriales se registra una may or proporción de agricultores a tiemp o parcial.

De todas las comarcas valencianas es en la Montaña donde encontramos un mayor porcentaje de empresarios trabajando en actividades no agrarias, concretamente el 43'8\% de todos los jefes de explotación. Paradójicamente, el porcentaje de ayudas familiares ocupados en la industria y/o los servicios (el 28’2\%) es uno de los más bajos. A grandes rasgos, esta comarca coincide con la geográfica de les Valls d'Alcoi. La industria (textil, papelera, etc.) se ha impuesto a una agricultura esencialmente de secano con predominio del policultivo arbóreo (olivo, almendro y frutales), adquiriendo una gran exp ansión la agricultura a tiempo parcial. Los sectores secundario y terciario se han convertido en complementos indisp ensables de la actividad agraria, la cual en gran medida les debe su subsistencia ${ }^{43}$.

Contrariamente a lo que se pudiera esperar, en el norte de la provincia de Castelló y en comarcas del interior de la de València, poco industrializadas, y alejadas de los principales centros urbanos e industriales del País, se registran algunos de los porcentajes más altos de campesinos dobleempleados en actividades no relacionadas con la agricultura. Más que a la oferta de empleos secundarios y terciarios, los resultados deben relacionarse con las escasas posibilidades del secano para generar empleo asalariado. Muchos alternantes deben ocuparse en la industria y los servicios como trabajadores autónomos.

En el litoral alicantino (comarca Central) tienen gran importancia relativa los camp esinos ocupados en actividades no agrarias. Los empleos industriales, y la concentración del sector turístico-hostelero, y de las funciones administrativas, son los que, sin duda, ocupan al 36'6\% de los empresarios y al $40 \%$ de los ayudas familiares; es decir, a casi la totalidad de los agricultores a tiempo parcial activos. Aquí, la expansión del fenómeno, como en Baleares y Canarias, está en relación con el desarrollo turístico de los años sesenta ${ }^{44}$; de ello es un claro exp onente el municipio de Benidorm, cuya población activa agraria ha sufrido una drástica reducción, los 262 agricultores de 1960 se han quedado en 66, en $1981^{45}$. 


\section{Conclusión}

Vamos a esbozar algunas conclusiones que nos sugieren los comentarios sobre el Censo Agrario de 1982.

a) La agricultura a tiempo parcial predomina en las explotaciones modestas.

Al comparar los niveles de importancia del fenómeno con la dimensión de las explotaciones, confirmábamos la mayor implantación de la agricultura a tiempo parcial en las comarcas más minifundistas. Para el conjunto del País los siguientes datos son muy elocuentes, el $44 \%$ de los empresarios posee menos de 1 Ha de superficie agrícola utilizada, y el 30’6\% de los ayudas familiares vive en explotaciones que no superan esta dimensión.

El predominio de la agricultura a tiempo parcial en las pequeñas explotaciones se pone de manifiesto si se atiende la sup erficie ocupada. En 1972 (el último Censo Agrario no ap orta datos a este respecto), los emp resarios alternantes contaban con una superficie media de 3'23 Ha, esto es, la mitad de la superficie que por término medio poseían los agricultores a tiempo completo (6’69 Ha).

Las miniexplotaciones pueden considerarse casi en su totalidad de tiempo parcial. Pero, los alternantes también poseen parte de las explotaciones de may or tamaño. Si en la pequeña exp lotación las precarias rentas agrarias, derivadas de las escasas dimensiones, fomentan la doble actividad del campesinado, en las explotaciones may ores los motivos de la alternancia son bien distintos, los empresarios tienen una mejor posición social y económica, por lo general viven fuera de la comarca donde tienen las tierras, y en ningún caso la agricultura constituye el sustento vital ${ }^{46}$.

b) En fecha reciente se ha producido una notable expansión del fenómeno.

En los últimos años (1972-1982), el País Valencià ha conocido una rápida expansión de la agricultura a tiempo parcial, a tal punto que en la actualidad cuatro de cada cinco miembros de la familia camp esina pueden ser considerados como agricultores a tiemp o parcial, bien porque tengan una actividad remunerada en el exterior, o bien porque se encuentran en «otra» situación. En 1972, la relación era de tres agricultores «a ratos» por cada agricultor «puro».

El incremento del número de alternantes, y el descenso de la cifra de agricultores a tiemp o completo, ponen de manifiesto que buena parte de las explotaciones que eran viables en 1972 han dejado de serlo diez años más tarde, lo que debe relacionarse con la progresiva fragmentación de las estructuras agrarias, que resta rentabilidad a unas explotaciones cada vez más pequeñas. De manera que el reducido tamaño de la explotación obliga al empresario y a sus familiares a buscar una ocupación externa.

Con ser importante, este tipo de alternante no es el único. También han contribuido a la expansión del fenómeno quienes han accedido a la titularidad de la tierra después de haberse iniciado en la actividad externa, bien por herencia o p or compra, como forma de inversión, entre los que predominan los propietarios urbanos ${ }^{47}$, que han sido los auténticos emprendedores de las transformaciones de las laderas en naranjal ${ }^{48}$.

En definitiva, y como conclusión más importante, es la escasa dimensión de las explotaciones la que lanza a buena parte de nuestros campesinos hacia la 
práctica de la doble actividad. Pero, también deben considerarse como alternantes, y de hecho constan en las estadísticas, los propietarios para los que «la agricultura es sólo una consecuencia de inversiones en tierras, sea por el motivo que fuere, ya que su ocupación principal son las profesiones liberales, la industria, el comercio ciudadano o de exp ortación, y la administración ${ }^{49}$.

c) La distribución del campesinado muestra diferencias según el tipo de ocupación principal.

Los camp esinos con ocupación externa, agraria o no, predominan en una amplia franja litoral. Al proceso de industrialización-urbanización se añade la existencia de una intensa agricultura de regadío dirigida a la exp ortación. Los mayores índices de empleo agrario se alcanzan en áreas de cultivo naranjer ${ }^{50}$, lo que se debe relacionar con el reducido tamaño de las unidades de explotación y con la especial organización del trabajo en la recolección de la naranja; también debe contribuir la proliferación de explotaciones adscritas a profesiones liberales, los cuales emplean mano de obra asalariada.

Hacia el interior, y sobre todo al norte del País, disminuye considerablemente la proporción de jornaleros, en función del secano extensivo imperante, incap az de generar empleo asalariado. Si a esto añadimos la escasa implantación industrial y la distancia a las principales aglomeraciones urbanas, los niveles de importancia de la agricultura a tiemp o parcial tienen que ser necesariamente inferiores a los del litoral. Apenas hay asalariados agrícolas, quienes comparten el trabajo de la exp lotación con una actividad externa serán trabajadores autónomos, y, en menor prop orción, emp leados. Aunque no se debe descartar que parte de los miembros de la familia campesina se desplacen fuera de su localidad de residencias, incluso a comarcas vecinas, p ara desemp eñar su segunda actividad, la más importante en tiempo y rentas obtenidas.

En definitiva, el tip o de ocupación depende de las posibilidades de empleo de cada zona. En el litoral, la concentración industrial y la agricultura comercial hacen que los tres sectores económicos, primario, secundario y terciario, pugnen por el primer puesto en la oferta de empleo. En el interior, el secano extensivo no puede hacer la competencia a la industria y los servicios en el mercado de trabajo, pese a su escasa importancia.

Además de los campesinos con ocupación principal en la industria y los servicios, y de los jornaleros, hay un tercer grupo de alternantes, el de los agricultores que ni trabajan la may or parte de su tiempo en la explotación ni ejercen una actividad remunerada en el exterior; tienen «otra» ocup ación principal y representan aproximadamente la mitad de los miembros de la familia campesina. Sería muy interesante saber a qué se dedican. Si se trata de pensionistas y amas de casa -que deben ser la mayoría-, es obvio que trabajan o dirigen las explotaciones personas alejadas de la actividad agraria. La distribución de este colectivo debe guardar relación con el envejecimiento, coincidiendo algunos de los valores más altos con las áreas de mayor decrecimiento demográfico en los últimos años ${ }^{52}$.

Como ha señalado el profesor Gozálvez, «si las explotaciones continúan fraccionándose, tanto a nivel de minifundio como a nivel de explotaciones medianas y grandes, nos veremos abocados en el País Valenciano a una generalización 
absoluta de la agricultura a tiempo parcial» ${ }^{53}$, a ello contribuirá también el alejamiento de la tierra por parte de los hijos de los actuales jefes de explotación, que prefieren un trabajo en la industria y los servicios, de manera que cuando ellos hereden la tierra se convertirán en agricultores a tiempo parcial. También hay que tener en cuenta las inversiones en tierras, cada vez más frecuentes, por parte de miembros de profesiones liberales.

\section{NOTAS BIBLIOGRÁFICAS}

1 JORDAN GALDUF, J. M. y SÁNCHEZ AYUSO, M. «La agricultura en el País Valenciano (situación actual)», Agricultura y Sociedad, n. ${ }^{\circ}$ 2, 1977, p. 241.

2 GOZÁLVEZ PÉREZ, V. «Tendencias actuales de la agricultura valenciana», Cuadernos de Geografía, n. ${ }^{\circ}$ 25, València, 1979, p. 150.

3 FONT DE MORA, R. «La agricultura valenciana», incluido en Estudio Económico. Región Valenciana, INDUBAN, 1975, pp. 49-67.

4 CUCO-FABRA-JUAN-ROMERO. La qüestió agrària al País Valencià, Ed. Aedos, Barcelona, 1978, p. 97.

5 GOZ ÁLVEZ PÉREZ, V. Ob. cit., p. 151; ARNALTE ALEGRE, E.: Agricultura a tiempo parcial en el País Valenciano: naturaleza y efectos del fenómeno en el regadío litoral, Ministerio de Agricultura, Madrid, 1980, pp. 239-320.

6 ARNALTE ALEGRE, E. Ob. cit., pp. 121 en adelante. Un comentario de este trabajo ha sido realizado por Miren Etxezarreta, publicado en Agricultura y Sociedad, n. ${ }^{\circ}$ 17, 1980, pp. 242-245.

7 Cuyos resultados fueron recogidos por NAREDO, M. La evolución de la agricultura en España, Ed. Laia, Barcelona, 1974, p. 102.

8 ETXEZARRETA ZUBIZARRETA, M. La agricultura insuficiente, Ministerio de Agricultura, Madrid, 1985, p. 154. Según los resultados de este trabajo el País Valencià se ve sup erado por los valores más altos de Albacete y Murcia.

9 GARCÍA MANRIQUE, E. «La agricultura a tiempo parcial en España. Comentario al Censo Agrario de 1972», Paralelo 37 , n. $^{\circ}$ 1, Colegio Universitario de Almería, 1977, p. 139.

BENELBAS i TAPIERO, L. A. Economía Agrària de Catalunya, Ketres, Barcelona, 1981, p. 129.

10 ETXEZARRETA ZUBIZARRETA, M. Ob. cit., p. 148.

11 No es posible hacerlo para los ay udas familiares, ya que el Censo Agrario 1972 no ap orta este tip o de información.

12 VIRUELA M ARTÍNEZ, R. «La agricultura a tiempo parcial en España», Estudios Geográficos, n. ${ }^{\circ}$ 187, Madrid (1987) pp. 211-238.

13 Esta situación ha sido destacada en Andalucía. Véase CRUZ VILLALÓN, J. y otros: «La agricultura a tiemp o parcial como sistema de vida en el medio rural andaluz», Revista de Estudios Agro-Sociales, n. ${ }^{\circ}$ 138, octubre-diciembre 1986, p. 140.

14 MARQUÉS, J. V. «Trabajar en el País Valenciano», incluido en Gaviria, M.: Ni desarrollo regional ni ordenación del territorio: el caso valenciano, Ed. Turner, S.A., Madrid, 1974, p. 94.

15 GOZÁLVEZ PÉREZ, V. Ob. cit., p. 150.

16 Las inversiones en tierras por parte de la burguesía y de las clases medias y profesionales 
urbanas ya fue asimismo destacada por GIRALT, E.: «Problemas históricos de la industrialización valenciana», Estudios Geográficos, n. ${ }^{\circ}$ 112-113, M adrid. 1968, pp. 389-393.

17 Véase la definición de campesinos con «otra» ocupación principal. I.N.E.: Censo Agrario de España 1982. Resultados Provinciales, t. III, Castellón, Madrid, 1984, p. 70.

18 El último Censo Agrario utiliza esta división comarcal. Véase a este respecto I.N.E.: ob. cit., «Notas metodológicas», p. VIII.

19 BENELBAS i TAPIERO, L. A. Ob. cit., p. 130; ARNALTE ALEGRE, E. Ob. cit., p. 103.

20 CUCO-FABRA-JUAN-ROMERO. Ob. cit., p. 99.

21 BARCELÓ-GENOVÉS-SORNI. «Bases para el planteamiento de una política agraria en la Comunidad Valenciana», Primer Congres d'Economía Valenciana, Artes Gráficas Morvedre, València, 1984, p. 16.

22 PÉREZ CASADO, R. «L'Agricultura», en Lluch, E.: L 'Estructura Económica del País Valencià, L’Estel, València, 1970, vol. I, p. 258.

23 La información que da el Censo Agrario acerca de la dimensión de las explotaciones, es otra de las razones p or las que nos hemos inclinado por la división comarcal del Ministerio de Agricultura. En las comarcas se indica el número de explotaciones inferiores a $1 \mathrm{Ha}$; en los municipios, la primera categoría dimensional es la de explotaciones menores de $5 \mathrm{Ha}$.

24 Véase a este respecto CUCO-FABRA-JUAN-ROMERO: Ob. cit., pp. 88-92.

25 PÉREZ PUCHAL, P. Geografía de la Població Valenciana, L’Estel, Valencia. 1976, pp. 111-113.

GOZÁLVEZ PÉREZ, V. «Cambios recientes en la población valenciana», en Estudis sobre la Població del País Valencià, Arts Gràfiques Soler, S.A., Valencia, 1988, pp. 678-687.

26 Debemos señalar que la clasificación se ha hecho atendiendo fundamentalmente a la actividad del titular, ya que es el que dirige la explotación y organiza las tareas de los otros miembros del hogar. No obstante, en todo momento nos referiremos a las actividades que desempeñan los ayudas familiares.

27 BERNAT i M ARTÍ, J. S. Problemática de un núcleo rural valenciano, Diputació de Castelló, 1986, p. 141.

28 PÉREZ CASADO, R. «Camp i ciutat al País Valencia recent», L 'Espill, n. ${ }^{\circ}$ 1-2, 1979, p. 49.

29 BURRIEL DE ORUETA, E. L. La Huerta de Valencia. Estudio de Geografía Agraria, Institución Alfonso el Magnánimo, Valencia, 1971, pp. 529-319.

30 PREVASA. Situación actual, problemas y perspectivas de las comarcas valencianas. Vega Baja del Segura, Caja de Ahorros de Valencia, 1982, p. 22; VERA REBOLLO, J. F.: Tradición y cambio en el campo del Bajo Segura, Instituto de Estudios Alicantinos, Alicante, 1984, p. 142.

31 BAILA PALLARES, M. A. Dinámica y estructura de la población de Vinaròs (1857-1981), Ajuntament de Vinaròs, 1983, pp. 150-157.

$32 \quad$ BURRIEL DE ORUETA, E. L. Ob. cit., p. 317.

33 PREVASA. Ob. cit., Ribera Baixa, p. 19.

34 FONTAVELLA, V. La huerta de Gandía, Instituto Juan Sebastián Elcano (CSIC), Zaragoza, 1952, pp. 105-107.

35 CUCO i GINER, J. Propietarios y jornaleros en dos pueblos valencianos, Institució Alfons el Magnànim, Diputació de València, 1982, p. 269.

36 PÉREZ PUCHAL, P. El paisaje agrario del Bajo Palancia, Institución Alfonso el Magnánimo, 1968, p. 119. 
38 MIRA, J. F. «Los valencianos y la tierra», Expresiones Actuales de la Cultura de un Pueblo, Centro de Estudios Sociales del Valle de los Caídos, Madrid, 1976, p. 58.

39 BARCELÓ-GENOVÉS-SORNI. Ob. cit., p. 16.

40 CUCO i GINER, J. y JUAN i FENOLLAR, P. «Las industrias agroalimentarias en áreas rurales: el caso de la Pobla del Duc (la Vall d'Albaida)», Estudios Territoriales, n. ${ }^{\circ}$ 13-14, 1984, p. 69.

41 CUCO i GINER, J. Propietarios y jornaleros..., ob. cit., p. 145.

42 M AT ARREDONA COLL, F. «Estructuras agrarias en el Alto Vinalopó», Estudios Geográficos, n. ${ }^{\circ}$ 165, Madrid, 1981, p. 444.

43 COST A MAS, J. «Explotaciones agrarias en les Valls d'Alcoi: el mas, la empresa familiar y el agricultor alternante», Investigaciones Geográficas, n. ${ }^{\circ}$ 3, Alicante, 1985, p. 84.

44 ÁLVAREZ ALONSO, A. «Los factores de supervivencia de una agricultura de secano. El caso de la isla de Lanzarote», en Paisajes Rurales de España. A.G.E., Valladolid, 1980, p. 339; SALVA TOMÁS. P. A.: «La agricultura a tiempo parcial en las islas Baleares», VII Coloquio de Geografía, Pamplona, 1981, p. 559; BURRIEL DE ORUETA, E. L.: Canarias: población y agricultura de una sociedad dependiente, Oikos-Tau, Barcelona, 1981, p. 123; GARCÍA RODRÍGUEZ, M.; HERNÁNDEZ PEÑATE, M. ${ }^{a}$ L.; INIESTA ALONSO-SAÑUDO, A.: «Contribución al conocimiento de la agricultura a tiempo parcial en Canarias. Una aproximación cuantitativa», IV Coloquio Nacional de Geografía Agraria. Canarias. 1987, p. 417.

45 CLAVER CORTÉS, M. ${ }^{a}$ C. "Benidorm: inmigración y población activa (1960-1981)», Estudis sobre la Població del País Valencià, Arts Gràfiques Soler, S.A., València, 1988, p. 973.

46 Estas apreciaciones se recogen en el informe PREVASA. Véase, por ejemplo, los cuadernos de las comarcas: Canal de Navarres-Enguera, p. 20; Xelva, p. 20, y Villar del Arzobispo, p. 19. En esta categoría de empresarios se incluirían aquellos para los que -según Gozálvez- la agricultura es sólo una consecuencia de las inversiones en tierra. GOZÁLVEZ PÉREZ, V. «Nuevos espacios agrícolas intensivos en el País Valenciano», Coloquio Hispano-Francés sobre espacios rurales, Madrid, 1983, pp. 146-147.

48 GOZÁLVEZ PÉREZ, V. «Las transformaciones de las laderas en naranjal en el País Valenciano», Paisajes Rurales de España, A.G.E., Valladolid, 1980, p. 302.

49 GOZÁLVEZ PÉREZ, V. Tendencias actuales de la agricultura valenciana», ob. cit., p. 150.

50 La elevada proporción de miembros de la familia con ocupación principal ext erna en actividad agraria que se observa en el litoral coincide con el may or volumen de agricultores por cuenta ajena. La concentración de temporeros en la costa de Castelló y Alacant ha sido estudiada por VIRUELA MARTÍNEZ, R.: «La población activa agraria en la provincia de Castelló»; y SEGRELLES SERRANO, J. A.: «Distribución espacial de la población activa agraria en la provincia de Alicante en la actualidad», en Estudis sobre la Població del País Valencià, Arts Gràfiques Soler, S.A., València, 1988, pp. 707-732, y 733-744, respectivamente. Aunque no disponemos de datos para la provincia de València, la distribución debe ser semejante a la de las otras dos provincias.

51 Como hacen muchos agricultores de Tales, que tienen su ocupación principal en fábricas de cerámica de l'Alcora, o los de Fondeguilla que acuden a los establecimientos de calzado de la Vall d’Uixó. Véase a este respecto, MIRA, J. F.: Els 
valencians i la terra, ed. 3 i 4, València, 1978, p. 133; VIRUELA MARTÍNEZ, R.: «La Vall d'Uixó: estructura profesional de un núcleo industrial e inmigratorio (1940-1975)», Cuadernos de Geografía, n. ${ }^{\circ}$ 26, Valencia, 1980, p. 76.

52 GOZÁLVEZ PÉREZ, V. «Cambios recientes en la población valenciana», ob. cit., p. 684.

53 GOZÁLVEZ PÉREZ, V. «Tendencias recientes de la agricultura valenciana», ob. cit., p. 155. 